\title{
Aantekeninge/Notes
}

\section{Fair deuce: an uneasy fair dealing-fair use duality}

\section{Introduction}

At the consultations between the Department of Trade and Industry and major stakeholders on 11 and 27 August 2015, brought on by the publication of the Copyright Amendment Bill (GN 642 (2015-07-27); GG 39028), the importance of users' entitlements was emphasised in excellent presentations and insightful commentary elaborating on this theme. The intention of this note is to continue this dialogue and the numerous published comments by deconstructing the fair use amendment proposed by section 14 of the Amendment Bill, to be known as section 12A of the Copyright Act 98 of 1978.

The bill engenders a disharmonious marriage of two distinct but integrally related empowering provisions, which was made clear during the August consultations. Section 12A of the bill instils confusion by creating a largely pointless, notionally discordant and thoroughly bizarre duality which provides so much matter for objection that this analysis is devoted entirely to it and cannot address the proposed additions to the current section 12 . This note gives in-depth commentary on the course set by the bill, specifically its attempts at crafting a fair dealing/fair use model. The approach is decidedly critical, punctuated by carefully considered proposals to optimise the balance between users' entitlements and owners' interests.

The developments envisioned by the bill certainly present some worthy trajectories which could set a visionary course for subsequent shaping of South African copyright law through the contextual and purposive interpretation of unique clauses. Notwithstanding this noble pursuit, the execution places overly-restrictive conditions on fair use, and the senseless differentiation between digital and analogue formats, purposes of use, and forms of expression must be questioned. The flaws in the proposed model are revealed to point out the fault lines in every user's legal position that it will expose if enacted, before proposing an alternative fair use/fair dealing hybrid.

\section{The Bill}

\section{The Conceptual Differences}

It is necessary to distinguish the doctrines of fair dealing and fair use. Fair dealing has its origin in the Imperial Copyright Act of 1911, which made provision for newspaper summaries (s 2(1)(i)), and expanded into section

How to cite: Shay 'Fair deuce: an uneasy fair dealing-fair use duality' 
12 of the current South African Copyright Act. Section 12 was initially based on section 6 of the English Copyright Act of 1956 then amended to its current form by the Copyright Amendment Act 125 of 1992 . It is thus a creature of statute, with (comparatively) clearly defined purposes and boundaries and a wealth of case law from many jurisdictions to clarify it. Fair dealing operates by exempting the use of copyright works for certain statutorily-defined purposes and only relates to particular types of works. The relative advantage of the fair dealing approach is that it provides more extra-judicial clarity to users who take the trouble to familiarise themselves with the statute, but this naturally comes at the cost of flexibility.

Fair use, by contrast, is a creation of the American bench first applied in Folsom $v$ Marsh ( $9 \mathrm{~F}$ case 342 1841) and subsequently taken up in statute, currently embodied in section 107 of the Copyright Law of the United States (17 USC 1978). It provides inherent flexibility by not restricting its application to a numerus clausus of permitted purposes of use, and is best understood as a mechanism to determine whether a user's conduct is fair rather than a set of requirements to be met (Hughes 'Fair use and its politics - at home and abroad' in Okediji (ed) Copyright Law in an Age of Exceptions and Limitations (2016) (forthcoming)). This presents a marked advantage to users and better embodies the broad array of public interest reasons that exist to legitimately use copyright works without prior authorisation or paying compensation. It enables transformative use of digital content for a perpetually expanding range of applications. The cornerstone attribute for the use to be allowed is fairness, which is also the substantive requirement of fair dealing (flanked by formal and threshold requirements).

These are the key differences between the two parallel doctrines. Already it should be clear that the two cannot operate in unison, as they serve the same function in different ways and fair dealing will be largely subsumed by fair use. There is no sense in retaining an expanded fair dealing exception (as proposed by s 13 of the Bill) and adopting a new, catch-all defence. Not only does this complicate matters unnecessarily, it compounds the risk of inherent linguistic and substantive contradiction as well as having an enormous area of convergence - effectively doing the same work, both being rendered cross-redundant. A blended model that replaces the existing fair dealing provisions and takes the nonexhaustive fair use approach - that enumerates the character of use that could fall under its protection - should instead be considered. This exception could also be invoked under circumstances that are in the public interest and meet the requisite fairness standard but which were not foreseen by the legislature. A critical analysis of the proposed amendments follows below.

\section{Section $12 \mathrm{~A}(1)$}

One laudable development is the generality of scope - the provision is not constrained to certain categories of works, as the current fair dealing 
exceptions are (parts of which do not apply equally across all categories of works). This represents a shift towards an open and inclusive approach that can adapt as and when creative culture requires it to. Unfortunately, this positive development is rivalled by numerous insertions that should not survive the redrafting of section 12A of the South African Copyright Act.

The very first subsection unnecessarily complicates matters by stating that 'fair use of work eligible for copyright includes the use by reproduction in copies, translation or by any other means'. It is difficult to extract cogent meaning from either part of this statement, but the latter part is the most contentious. It appears to derive from the relatively out-dated American provision which was drafted in a time when 'use by reproduction in copies or phonorecords or by any other means' (presumably an attempt at keeping its application technology-neutral) represented the most prudence that could be achieved in the context of the existing state of technology. However, because this provision was crafted by and for a foreign jurisdiction, it does not cater for South African law as it was not designed for it. For example, what about adaptations that are neither copies nor translations, like most parodies and countless other forms of use? The fair use provision was not created with adaptations in mind because American copyright law does not grant a separate right of adaptation and cases are decided on the question of whether there has been a reproduction of the original work. However, there is no reason that a direct infringement of the right to make an adaptation cannot be accommodated as fair use if the standard fairness assessment so concludes. Notwithstanding this formulation, the proposed fair use amendment injects confusion from the opening bid by adopting provisions piecemeal from a foreign template.

The standard fair dealing construction ("[c]opyright shall not be infringed by any fair dealing,, as contained in the current s 12(1)(a) of the South African Copyright Act) is preferable as it attains a more inclusive neutrality regarding technology, and indicates that all of the exclusive rights that comprise an owner's copyright are implicated. The phrase stems from fair dealing provisions but can confidently be used to accustom fair use to South African law, if that is the intention.

\section{Section $12 \mathrm{~A}(2)$}

The second subsection is a reiteration (arguably in a looser form) of some of the existing fair dealing purposes, but crucially employs the phrase 'for purposes such as' instead of the current 'for purposes of', which closes the list of the permitted types of conduct. This phrase performs the pivotal function of fair use and makes the list inclusive rather than exhaustive. Although its inclusion is to be commended, it should go further in crafting a uniquely South African contextualisation of the defence. It is submitted that the existing list of purposes, currently concentrated in section 12(1) but scattered throughout the subsequent 
subsections, be incorporated and consolidated here, as well as the additional provision for parody (see par 25 below).

Unfortunately, section 12(2) is too heavily based on the phrasing of the 1978 American exception (s 107 USC 17 supra), which can and should be improved in view of subsequent developments relating to the interpretation of the fair use defence and the expansion of subject-matter suitable for copyright protection - as well as the evolution of social and cultural context and needs in the intervening forty years since its statutory formulation. Such improvements are suggested below (see par 3 below).

\section{Section $12 \mathrm{~A}(3)$}

The (presumably unintended) effect of subsection (3) is worrying. The amendment reads:

Notwithstanding any provision of this Act, the use of digitised copyright material published in the internet [sic] and other electronic media shall be restricted for educational purposes, unless covered by an explicit notice for [sic] request for licence to use the digitised material.

Given that this provision immediately follows the central fair use exception itself, it must be read to refer to this use of 'digitised' content. The suggestion that fair use of any variety, other than for educational purposes, can only be undertaken in relation to analogue content is absurd. This provision goes against the very grain of the integral Technological Neutrality principle recognised worldwide (Craig 'Technological Neutrality: (Pre)Serving the Purposes of Copyright Law' in Geist (ed) The Copyright Pentalogy (2013) 271 -305), and seems to imagine that the prevalent methods of use have remained unchanged over the past few decades.

The limitation that this wording places on the fair use provision could relegate its utility to the margins. The practical effect of restricting fair use for criticism, comment, scholarship and even judicial proceedings to antiquated forms of media could render some industries (such as journalism) impossible to legitimately pursue, unless only print media is resorted to, and others (such as film review) virtually meaningless (if only films in analogue form can be used, as this will likely require obtaining such a format from the copyright owner, given the increasing scarcity of analogue material). There is no clear justification for this difference and it remains indefensible until it is made apparent that the effects have been properly considered and that it serves valuable objectives.

It would be nonsensical to read the fair dealing provisions (if still extant) to include digital content if its sister provision, which covers much (if not all) of the same ground, restricts such use to analogue material. Therefore, the fair dealing provisions would either validate conduct that the fair use provisions specifically exclude, or they would be 
reined in to comply with this new restraint. Both possibilities are to be avoided at all costs.

The problems with this provision do not end here. If a user wishes to invoke their fair use entitlement for any reason other than an educational one, they must first issue 'an explicit notice for [sic] request for licence to use the digitised material' (s 12A(3)).

On its kindest reading, this wording requires users to make a bona fide attempt to licence the use before proceeding with a fair use. Naturally, this places an immense burden on users to locate the owner of any material they wish to use and negotiate such use (which may, quite legitimately, not always be flattering to the owner's work). This undermines the rationale and purpose of fair use and repositions it as a mechanism exclusively for relieving market failure. This proviso must be rejected forthwith, as it would result in the end of fair use.

\section{Section $12 \mathrm{~A}(4)$}

The next provision is equally riddled with conceptual misunderstanding and misguided execution. It starts encouragingly enough by allowing for 'some limited and reasonable use of copyrighted work for purposes of cartoon, parody or pastiche work ... [sic]'. Evidently the bill seeks to exempt parody and similar uses of copyright works. It should be noted that currently the Copyright Act does not allow this type of use of copyright works, but section 16(1) of the Constitution of the Republic of South Africa, 1996, undoubtedly exempts this form of expression. The aim of the bill is plainly to carve out an exception in line with section 16 of the Constitution, thus lending valuable clarity to potential users and it should be retained in the bill after revision. However, this specification of purpose arguably contributes nothing to the exemption granted by section 12A(2) of the Copyright Act, as it is clear that the non-exhaustive nature of the exception will include free speech in the form of parody in line with section 16(1) of the Constitution. That said, specific recognition of this valuable form of expression is noble and potentially permits users greater confidence that their conduct is protected as fair use by codifying an existing constitutional right in a specific instance.

Ultimately, if it is to be included for purposes of extra-judicial certainty (which is recommended), this should be done in the general fair use clause along with the other typical purposes that direct its application. Listing a short variety of virtually synonymous terms is a characteristic of the fair dealing approach (s 30A of the United Kingdom's Copyright Designs and Patents Act of 1988 (pending promulgation); s 41A of the Australian Copyright Act 63 of 1968; s 29 of the Canadian Copyright Act (C-42) of 1985) and is peculiar to the fair use context, although unobjectionable in principle. That said, it is puzzling that 'cartoon' was chosen for inclusion above any other term, as a cartoon is a medium of expression rather than a form. A cartoon could constitute parody, but it could also be used as a vehicle for any other form of speech (such as 
political, commercial or even hate speech) or as an adaptation of virtually any literary work (where it would adapt the written narrative to a visual artistic narrative). It is preferable for a legislative provision to remain medium neutral and content specific, with substantive aims that reflect constitutionally-entrenched rights and freedoms.

This befuddlement aside, the remainder of the sentence warps its admirable inclinations. The provision continues:

for purposes of cartoon, parody or pastiche work [sic] in songs, films, photographs, video clips, literature, electronic research reports or visual art for non-commercial use, without having to request a permission [sic] specified in the Schedule hereto.

Dictating the form that a parody may take is unreasonably restrictive, especially when the forms are oddly specific without legislated definition: songs (presumably including the literary and musical works and potentially sound recordings); visual art (presumably covering most but not all of the forms listed in the definition of 'artistic work'); and both video clips and films (the latter presumably including video clips if the statutory definition of 'cinematograph film' is followed). Despite genuine interest, the author was unable to locate a parodying electronic research report and is confused - if intrigued - by what this wording could possibly refer to, or seeks to achieve. This may be a case of a confused preposition, but prepositions provide substantive meaning in legislation. If the preposition 'in' was perhaps mistakenly inserted instead of 'of', the sentence would change meaning completely. It would then allow parodies of songs, films, photographs, and video clips, which is a slightly better modus operandi, although misplaced in the fair use doctrine, belonging, again, to the fair dealing canon. However, there is no apparent reason - nor is it the norm internationally - to limit the parody exception to enumerated subject matter, perhaps other than those being the only conceivable types of copyright works that can meaningfully be parodied. This is evidently not the case here; the satirical performance of dramatic works being analogue works and website parodies being digital works that are excluded ex facie.

It is further questionable whether there is any basis to limit the availability of this exception to non-commercial uses, especially considering that this qualification creates confusion when read with subsection 5(d) (see par 26 below). The fallacy of equating commercial use with unfairness has been exposed and warned against by many foreign courts and governmental reviews that it is trite. At its softest construction, the non-commercial requirement will create a presumption of unfairness, and at its strictest, will completely invalidate the use of this exception in commercial instances. It is submitted that guidance should be sought from the numerous investigations undertaken by foreign governments into the use and value of allowing commercial parodies of similarly commercial works (Gowers Gowers Review of Intellectual Property (2006) recommendation 12; Hargreaves Digital Opportunity (2012) recommendation 5; McKeough Copyright and the Digital Economy 
(2014) recommendations 5-3; see also Shuttleworth Foundation South African Open Copyright Review (2008) recommendation 2 available from http://ip-unit.org/wp-content/uploads/2010/07/opencopyrightreport1.pdf (accessed 2015-04-22)).

Critically, the non-commercial rider should be removed from the proposed exception (currently inserted in the parody defence in s $12 \mathrm{~A}(4)$ ) in order to maximise the free speech benefit that it carries. There can, in principle, be no conceivable objection to commercial parodies, especially considering the established legal fact that speech (as protected by section 16 of the Constitution, and specifically parody as speech) can be commercial, as was the case in Laugh it Off CC $v$ South African Breweries International (Finance) BV t/a Sabmark (2005 (8) BCLR 743 (CC)) where it was condoned in relation to a trade mark. This accords with foreign case law from jurisdictions that have seen some use of their parody exceptions, where the commercial nature of the use invariably plays a role in determining fairness but does not disbar it from the outset (Campbell aka Luke Skywalker et al v Acuff-Rose Music Inc 510 US 569 (1994); Mattel v Walking Mountain Productions 353 F 3d 792 (9 Cir 2003)).

It must also be assumed that if the request for permission to use the work as the subject of a parody is turned down (which is not unlikely, given the nature of the request), the user may then rely on her fair use entitlement purportedly granted by this very section. This would presumably also be the case if the granting of permission is made contingent on financial consideration, given the purpose of fair use (which is to enable unauthorised and uncompensated use). Of course this raises the question of why the permission must be sought in the first place.

The referral to an appending schedule also seems to be a misfire, because this schedule does not refer to parody of works once, as it only relates to educational uses of translations - a decidedly different endeavour.

Subsection (4) then proceeds to state that the fair use for purposes of cartoon, parody or pastiche, as outlined above, includes:

(a) quoting the works of the copyright owner in a manner that is reasonable and fair;

(b) making copies of eBooks or compact discs purchased by the user; or

(c) transferring of purchased compact discs onto the user's MP3 format player.

The first of these enumerations demonstrates a misunderstanding of the parody mechanism and the latter two have nothing to do with it. Depending on the form of the original work and the consequent form of the parody (although inter-form parody is of course possible), quoting from a work is not a typical tactic of the parodist. Parodies usually constitute an adaptation of a work more than a reproduction, although 
the key elements (likely comprising a substantial part) of the original work must be present for the parody to assume that status (Visser 'The Location of the Parody Defence in Copyright Law' 2005 CILSA 342). If the original work is not recognisable in the derivative work, the parody has failed in its core aim and function (and, ironically, will neither qualify for nor need the present exception). Even if the subject were a literary work and thus susceptible to being quoted, quotation is resorted to more often by literary critics than by social commentators who choose parody as their form of commentary. A more common style of critiquing literary works is satire, which uses a recognisable element of the protected literary work such as its peculiar style, plot or themes and provides a satirical take on this element of the work or even society more broadly (Dr Seuss Enterprises v Penguin Books 109 F 3d 1394 (9th Cir 1997)).

Once relieved of the parody context in which they are currently anchored, the latter two provisions are valuable additions to South African copyright law, but should be formulated more broadly and crafted in a separate provision as it has nothing to do with fair use. The format shifting provisions (as they are known) allow users to convert media that they are in lawful possession of into another format and transfer these files onto a personal media device (e.g. 'WAV' files from a compact disc to 'MP3' on an electronic music playing device). This is another meaningful development but must be divorced from the fair use provision. However, it is imperative for the exception to go beyond its envisioned scope of music and eBooks, as well as to go beyond the restrictive formulation that only applies to music purchased in the form of compact discs - which is becoming increasingly rare - and enable the similar use of digitally purchased music and other media. It could also be worth investigating the inclusion of a tax imposed on electronic media devices to compensate copyright owners for their consequent loss of revenue.

\section{Section $12 \mathrm{~A}(5)$}

The standard factors for establishing the fairness of the use have been adopted, albeit amid some alteration. These factors have been taken largely from section 107 of the United States Copyright Law, replete with American terminology, and infused with existing provisions of the South African Copyright Act. The first three factors in section $12 \mathrm{~A}(5)$ are identical to the American counterpart, directing that the purpose and character of the use, the nature of the work, and the amount and substantiality of the portion used in relation to the work as a whole must be considered. This much can be accepted as an established part of the fair use doctrine, but the amendment then veers off course by imposing rigid quantitative thresholds on the last of the three factors mentioned. In addition to considering 'the amount and substantiality of the portion used in relation to the copyright work as a whole', section 12A(5) also requires that it must be considered: 
whether the use of the copyrighted work is fair and proportionate, by considering further that (i) the use of copyrighted work is of few lines [sic] of a song, literature [sic] or few parts [sic] of a film or art work [sic] for cartoon, parody or pastiche; (ii) the use of the whole copyrighted work for cartoon, parody or pastiche for commercial use shall require the issuance of licence [sic]; and (iii) the use of copyrighted work is compatible with fair practice in that the source and the name of the author are mentioned in the publication, broadcast, recording or the platform where the copyrighted work is displayed (italics in original).

This provision is quite inexplicable. It seems to relate only to determining whether a parody constitutes fair use, which triggers an internal interpretive implosion that would result in the entire allowance made for parody being rendered useless, and may have a similar impact on other types of use. If it is correct that sub-factors (i)-(iii) apply only to parodies, the reasons for which remain evasive, this would betray the complete misunderstanding of the practicalities of parodying expression, evidenced most starkly by the last of the three requirements which are discussed in due course.

The provision goes awry in the first clause, which neglects to state what the use should be proportionate to. The safest guess is probably that the use must be fair in proportion to the work as a whole, but this reading perfectly positions this new factor to subsume the relevance and function of the immediately preceding factor - that of 'the amount and substantiality of the portion used in relation to the copyright work as a whole'. So far it seems as if this fourth factor can be interpreted quantitatively and qualitatively, much like the third factor, but this purposeless - if benign - perspective is dismantled by what follows.

Setting quantitative limits on what constitutes fair use (as does section $12 \mathrm{~A}(5)(\mathrm{i}))$ defies the very purpose of the chief doctrine of user empowerment. Fair use is necessarily context-sensitive and will be rendered virtually impotent in many important current forms of application if quantitative restrictions, however vague (e.g. 'few parts of a film or artwork'), are imposed without distinction. Although this quantitative qualification is structured as an elaboration of the novel fourth factor for determining fairness, it reads as barring a finding of fairness on this factor if more than the permitted few lines/parts of a work is used, regardless of the qualitative importance of said lines/parts. The ex ante deeming of unfairness goes against the overriding qualitative nature of the fairness inquiry (although, interestingly and seemingly inconsistently, deeming provisions can be of tremendous value to users if inverted to deem conduct fair, thus discouraging litigation). The triedand-tested evaluation techniques associated with fair use should not be warped without reason.

The second factor enumerated by section 12A(5) does no better than its anterior counterpart, stating that a commercial parody that uses the whole copyright work shall require a licence and thus cannot be fair use. First, an absolute prohibition on commercial parodies - which is what 
the requirement of obtaining a licence does, thereby invalidating fair use by requiring consent - is senseless and without international precedent. As mentioned, fair use cases often involve a commercial use and nowhere has it been suggested that the presence of this attribute should prohibit a finding of fair use per se. While the commerciality of a parody should undoubtedly be considered in determining fairness, elevating this consideration to the status of the pivotal deciding - formalistically barring, even - element retraces the misguided steps in American jurisprudence following on the decision in Sony Corporation of America $v$ Universal Studios Inc (464 US 417 (1984)) that took decades to correct. In fact, this provision would go further even than the judicial misstep by creating a formalistic requirement, not a mere rebuttable presumption as did the Sony case.

Second, and crucially, the quantitative barrier imposed on users ignores the fact that often the essence of the whole work must be reproduced in order for the parody to hit its mark. Consider an artistic work such as a painting or photograph: if the artistic work achieves suitable fame or notoriety for it to be susceptible to popular parody, reproducing a small part of the painting or photograph will almost inevitably not sufficiently signify the original work. However, parody will never reproduce a work without modification, as this will simply and selfevidently not be parody. The focus of the parody justification should be on how transformative the use is, not how much of the original work is reproduced. Parody, much like the currently permitted purposes of use stipulated in section 12(1) of the Copyright Act, cannot be donned after the fact to validate brazen reproduction of a work without any parodying intention or modification.

The third subsection does not explicitly restrict itself to the parodying uses of copyright works, but, read with the antecedent subsections, it is not an unreasonable reading that this is the legislature's intention. If this is the case, it effectively prohibits any cartoon, parody or pastiche, in its currently prevalent form, where no attribution is given to the work that is being parodied (on the futility of this requirement in relation to parody, see Visser 2005 CILSA supra at 336-337). However, even on the preferable reading that this does not necessarily relate to parody only, the requirement is out-dated and the wording drastically restricts its utility in orchestrating fair use. The stipulation that the use must comply with 'fair practice' could be helpful if it is read as connoting fair practice of the particular industry to which the user belongs (if applicable). In other words, where the user reproduces a copyright work for a particular purpose - such as reporting on current events or reviewing the work such use should accord with standard practice in the particular industry, which could naturally vary from one profession to the next and will change as the industry does. However, to then constrict the manner of accreditation (which could potentially comply with standard practice for the industry, such as providing a hyperlink back to the original work if applicable, but does not adhere to the letter of the law) would effectively retrograde the proper context and application of this aspect of fair use to 
the analogue age, imposing an anachronous modus operandi on users in the digital space, even after the sensible finding in Moneyweb (Pty) Ltd $v$ Media 24 Ltd (2016 3 All SA 193 (GJ)) that providing a hyperlink back to the source can fulfil the requirement of sufficient acknowledgement.

It is submitted that if this requirement is found absolutely necessary (it is not a standard feature of fair use) the requirement of 'sufficient acknowledgement' (such as that found in s 30(2) of the English Copyright, Designs and Patents Act of 1988) should replace the dated and formalistic requirement that the source and name of the author be mentioned. Situating the admittedly broad 'sufficient acknowledgement' in a more concrete, but steadfastly ad hoc and interpretive context, can be achieved by retaining the reference to 'fair practice', if such phrase is taken to refer to the particular user's industry as suggested above.

The adoption of the final of the fifth factors from the American statute is unproblematic and is a valuable aid in determining whether the use would have a harmful impact on the incentive to create copyright works if it is sustained.

\section{Section $12 \mathrm{~A}(6)$}

Section 12A(6) continues in puzzling fashion by confining the first two subsections (the latter of which comprises the general fair use exception) to non-commercial uses. This seems to be an unwelcome bit of borrowing from the fair dealing model, which specifies that the use of a copyright work for some purposes should be non-commercial, such as 'private study' and 'personal or private use' (s 12(1)(a) of the Copyright Act). The problem in making this a blanket requirement is that some legitimate uses which are currently allowed (and should legitimately be allowed in future), are almost invariably for commercial gain. This includes news reporting and criticism or review of a work, both of which are contained in the inclusive list of characteristic purposes espoused by the amendments to section $12 \mathrm{~A}(2)$ as well as the existing section 12(1)(b)-(c). It also causes an ex facie inconsistency by insisting that all use undertaken in terms of subsection (2) be non-commercial, despite subsection (2) including 'professional advice' as an explicitly permitted purpose. Further, imposing the proposed ban on all commercial use would not only go against established doctrine and betray one function of the exception (which is to obviate market failure), it would render meaningless the context-sensitive application of numerous fairness factors (notably the considerations of 'the purpose and character of the use including, whether such use is of a commercial nature or is for nonprofit educational purposes' and 'the effect of the fair use upon the potential market for or value of the work'). This single-sentence subsection threatens to confuse and contort users' entitlements in unprecedented and unwelcome ways and should be done away with. 


\section{Section $12 \mathrm{~A}(7) \& 12 \mathrm{~A}(8)$}

The last two subsections of a very long section should not be present as they purportedly relate to parallel importation of trademarked goods and encryption of computer-generated data, which do not deal with fair use. It is possible that the last subsection is meant to protect users' entitlements under this section in relation to the legitimate circumvention of Technological Protection Measures (TPMs) to exercise fair use entitlements. However, there is nothing to suggest that this is the case as TPMs are regulated separately in the bill and there is a reinforcing provision aimed at protecting such entitlements in section 28P of the Copyright Amendment Bill (which tragically forgets to specify s 12A along with the other 'general public interest exceptions', such as the current s 12).

Space does not allow for expanding this critique to the related subsequent provisions relating to exceptions for educational purposes, persons with disabilities, and libraries, but the prognosis for these provisions is no better than for section 12A.

\section{Further Proposals}

A deeming provision such as that found in section 40(5) of the Australian Copyright Act, which relates only to use for purposes of research and study, should be considered as scholars and librarians would benefit enormously from clear but malleable quantitative guidelines, and any use that exceeds the relevant threshold must be justified as usual.

One particularly significant function that this exception could play in South African law is enabling the use of copyright works for the transformative creation of derivative content by Internet users. This flourishing environment of creativity should be accommodated and nourished by copyright law, as copyright owners could potentially assert their rights simply to silence user-cum-creators of their works (users that engage in transformative use of copyright works to create new, derivative works). Fair use is more permissive towards such unauthorised use, which makes it more valuable than fair dealing on this point.

The fair use provision should enumerate a non-exhaustive list of conceivable purposes that may be judged to be fair in order to characterise the type of use that the legislature intends to cater for. This has been achieved for the most part, but it is submitted that the characteristic purposes should be amended to better suit the core purpose of the provision. If a proper preamble is supplied, purposive interpretation becomes significantly more focused on producing the desired outcome. Currently, the proposed provision lacks context, vision and imagination, all of which are necessary to craft a new benchmark fair use exception. Many of the bill's intended objectives can be salvaged, but 
only if these objectives are clearly stated in the preamble or in policy which, unfortunately, has also not been adequately achieved.

RM SHAY

University of South Africa 